\title{
Hubungan Pengetahuan, Sikap, dan Dukungan Unit Kerja/Departemen dengan Pemberian Air Susu Ibu Eksklusif pada Tenaga Kesehatan Rumah Sakit Hasan Sadikin
}

Ariani, Kusnandi Rusmil, Tetty Yuniati

Departemen Ilmu Kesehatan Anak Fakultas Kedokteran Universitas Padjadjaran/Rumah Sakit Dr. Hasan Sadikin, Bandung

Latar belakang. Faktor yang memengaruhi pemberian ASI eksklusif pada ibu bekerja adalah pengetahuan, sikap, dan dukungan institusi. Petugas kesehatan berperan ganda, yaitu sebagai ibu bekerja dan panutan praktek pemberian ASI.

Tujuan. Memperoleh hubungan antara pengetahuan, sikap, dukungan unit kerja terhadap praktek pemberian ASI eksklusif oleh tenaga kesehatan di Rumah Sakit Umum Dr. Hasan Sadikin (RSHS).

Metode. Penelitian cross-sectional dengan metode consecutive sampling, dilakukan pada bulan Januari-Maret 2016 pada peserta program pendidikan dokter spesialis (PPDS), peserta program pendidikan profesi dokter (PSPD), perawat, dan bidan wanita; berusia $\leq 37$ tahun; bekerja atau belajar di RSHS; memiliki anak lahir tunggal berusia 6-24 bulan; mengisi kuesioner dan dianalisis dengan multivariat Hasil. Pengetahuan (OR IK95\%=3,7; p=0,013) dan dukungan tenaga kesehatan (OR IK95\%=3,45; p=0,031) berhubungan dengan praktek pemberian ASI eksklusif.

Kesimpulan. Pengetahuan ibu berhubungan dengan praktek pemberian ASI eksklusif, sementara dukungan unit kerja/departemen dan sikap tidak berhubungan dengan hal itu. Dukungan petugas kesehatan merupakan faktor perancu yang berhubungan dengan hal tersebut. Sari Pediatri 2016;18(1):45-9

Kata kunci: ASI eksklusif, pengetahuan, sikap, dukungan institusi, petugas kesehatan

\section{The Relationship between Knowledge, Attitude, Institutional Support, an Exclusive Breastfeeding Practice by Health Care Workers in Hasan Sadikin General Hospital}

Ariani, Kusnandi Rusmil, Tetty Yuniati

Background. Many factors influenced working mothers to provide exclusive breastfeeding. Among these factors are knowledge, attitude, and institutional or place of work support. Health care worker mothers have dual roles: which are working and breastfeeding practice role models.

Objective. This research was conducted to obtain the relationship between knowledge, attitude, institution support, and exclusive breastfeeding practice by health care workers in Hasan Sadikin General Hospital (RSHS).

Methods. This is a cross-sectional study with consecutive sampling method, conducted from January through March 2016, among female residents, clinical clerks, nurses, and mmidwives aged $\leq 37$ years old, who were working or studying at RSHS; having a singleborn child aged 6-24 months; fulfill questionnaires and the data were analyzed with multivariat.

Results. Knowledge (OR CI95\%=3.7 p=0.013) and other health care worker's support (OR CI95\%=3,45 p=0.031) were related to exclusive breastfeeding practice.

Conclusions. Mother's knowledge was related to the exclusive breastfeeding practice while institution support and attitude were not related to it. Other health care worker's support was the confounding factor. Sari Pediatri 2016;18(1):45-9

Key words: exclusive breastfeeding, knowledge, attitude, institution support, health workers

Alamat korespondensi: Dr. Ariani. Departemen Ilmu Kesehatan Anak Fakultas Kedokteran Universitas Padjadjaran/Rumah Sakit dr. Hasan Sadikin Bandung. Jl. Pasteur No. 38 Bandung 40163, Indonesia, Tel. +62 (22) 3035957. E-mail: raisya.alkhansa@gmail.com 


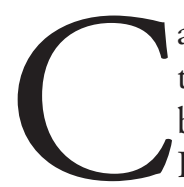

akupan pemberian ASI eksklusif pada tahun 2012 secara global maupun di negara berkembang hanya 39\%. ${ }^{1}$ Menurut Riset Kesehatan Dasar (Riskesdas) 2013, cakupan pemberian ASI eksklusif di Indonesia 30,2\%. ${ }^{2}$ Di Jawa Barat, angka cakupan pemberian ASI eksklusif 31,25\%, hampir sama dengan tingkat nasional. Sementara pada tingkat kota/kabupaten di Jawa Barat, Kota Bandung menempati peringkat ketujuh terbawah dari 26 kota/ kabupaten, dengan persentase pemberian ASI eksklusif $14,7 \% .^{3}$

Bayi yang disusui secara penuh selama 3-4 bulan pertama kehidupannya lebih sedikit menderita berbagai penyakit, antara lain, gastroenteritis, infeksi saluran pernapasan, otitis media, infeksi saluran kemih, dan enterokolitis nekrotikan. ${ }^{4,5}$ Edmond $\mathrm{dkk}^{6}$ menyimpulkan bahwa persentase kematian neonatus dapat dikurangi $22 \%$ jika saja bayi disusui dalam satu jam pertama kehidupannya dan 16\% jika mulai disusui dalam 24 jam pertama. Jones $\mathrm{dkk}^{7}$ menyatakan jika 90\% bayi diberi ASI maka sekitar 1,3 juta kematian anak di seluruh dunia setiap tahun dapat dicegah.

Penelitian Roig dkk, ${ }^{8}$ Obilade, ${ }^{9}$ dan Haroon $\mathrm{dkk},{ }^{10}$ menemukan bahwa pengetahuan memengaruhi pemberian ASI eksklusif. Hasil penelitian Abdullah dan Ayubi ${ }^{11}$ menunjukkan faktor yang berhubungan dengan pemberian ASI eksklusif adalah sikap, ketersediaan fasilitas, dan dukungan pengasuh. Johnston dan Esposito $^{12}$ menemukan bahwa dukungan tempat kerja meningkatkan keberhasilan ibu di Amerika. Faktor lain yang memengaruhi pemberian ASI eksklusif, antara lain, pendidikan, jenis persalinan, dukungan suami, dukungan teman, dukungan pengasuh, dukungan petugas kesehatan, promosi susu formula, ibu yang bekerja, ibu merokok, dan usia ibu. ${ }^{13,14}$

Penelitian mengenai pengaruh pengetahuan, sikap, dan dukungan tersebut terhadap keberhasilan ASI eksklusif pada non-tenaga kesehatan sudah banyak diteliti. Namun, sampai saat ini, belum ada penelitian mengenai hubungan pengetahuan, sikap dan dukungan tempat bekerja dengan praktik pemberian ASI di kalangan tenaga kesehatan di Indonesia. Penelitian ini bertujuan menentukan hubungan sikap, pengetahuan dan dukungan unit kerja/departemen terhadap praktik pemberian ASI eksklusif pada anak peserta program pendidikan dokter spesialis (PPDS) dan program studi profesi dokter (PSPD), bidan, serta perawat Rumah Sakit Dr. Hasan Sadikin (RSHS) dengan mengikutsertakan berbagai faktor lainnya yang berhubungan dengan pemberian ASI eksklusif.

\section{Metode}

Penelitian analitik dengan rancangan potong lintang pada PPDS, PSPD, bidan, dan perawat RSHS. Kriteria inklusi adalah PPDS, PSPD, bidan dan perawat wanita berusia $\leq 37$ tahun, bekerja atau belajar di RSHS, mempunyai anak yang lahir tunggal, serta cukup bulan berusia 6-24 bulan. Kriteria eksklusi adalah merokok, terdapat kontraindikasi medis pemberian ASI dalam 6 bulan pertama setelah lahir.

Responden mengisi kuesioner yang sudah divalidasi melalui penelitian pendahuluan, terdiri atas data dasar, pertanyaaan pengetahuan, sikap dukungan unit kerja/departemen dan praktik pemberian ASI ekslusif. Pertanyaan mengenai pengetahuan, sikap dan dukungan unit kerja/deprtemen beberupa pertanyaan tertutup dengan jawaban "ya" atau 'tidak". Jawaban pertanyaan pengetahuan, sikap, dan dukungan kemudian dilakukan skoring dengan skor skala 100.

Analisis bivariat untuk variabel kategorik digunakan uji Chi-square, data numerik dengan Mann Whitney. Faktor yang memiliki nilai $\mathrm{p}<0,25$ pada hasil analisis bivariat akan dimasukkan ke dalam analisis multivariat menggunakan regresi logistik untuk mencari faktor yang berhubungan dengan pemberian ASI eksklusif. Faktor dianggap bermakna apabila memiliki nilai $\mathrm{p}<0,05$. Pengolahan data statistik dilakukan dengan menggunakan program SPSS versi 20 for windows.

\section{Hasil}

Penelitian dilaksanakan pada bulan Januari sampai Maret 2016 terhadap PPDS, PSPD, bidan, dan perawat RSHS. Delapan puluh lima subjek bersedia ikut serta dalam penelitian, 75 orang memenuhi kriteria inklusi penelitian. Karakteristik subjek penelitian tertera pada Tabel 1 .

Usia anak median lebih muda pada kelompok yang tidak memberikan ASI eksklusif. Sebagian besar responden melahirkan bukan di RSHS. Pekerjaan suami responden lebih banyak yang bukan tenaga kesehatan. Sebagian besar responden meninggalkan bayi lebih dari 50 jam per minggu dan pernah memberikan ASI eksklusif. 
Ariani dkk: Hubungan pengetahuan, sikap, dan dukungan unit kerja/departemen dengan pemberian ASI eksklusif pada tenaga kesehatan

Tabel 1. Karakteristik subjek penelitian

\begin{tabular}{lcc}
\hline Variabel & \multicolumn{2}{c}{ Pemberian ASI eksklusif } \\
\cline { 2 - 3 } & Ya & Tidak \\
& $\mathrm{n}=48$ & \\
& & \\
Usia anak & $13,75(6,0)$ & $11,63(5,1)$ \\
$\quad$ X (SD) & 13 & 10 \\
$\quad$ Median & $6-24$ & $6-24$ \\
$\quad$ Rentang & & \\
Tempat melahirkan & 24 & 12 \\
$\quad$ RSHS & 24 & 15 \\
$\quad$ Bukan RSHS & & \\
Pekerjaan suami & 18 & 13 \\
$\quad$ Petugas kesehatan & 30 & 14 \\
$\quad$ Bukan petugas & & \\
$\quad$ Kesehatan & & \\
Lama meninggalkan bayi \\
(per minggu) \\
$\quad<50$ jam \\
$\quad>50$ jam & 20 & 12 \\
Pengalaman memberikan & 28 & 15 \\
ASI eksklusif & & \\
$\quad$ Ya & & 16 \\
Tidak & 25 & 11 \\
\hline
\end{tabular}

Tabel 3. Hubungan skor pengetahuan, sikap, dan dukungan dengan pemberian ASI eksklusif

\begin{tabular}{|c|c|c|c|}
\hline \multirow[t]{2}{*}{ Variabel } & \multicolumn{2}{|c|}{ ASI eksklusif } & \multirow{2}{*}{$\begin{array}{c}\text { Nilai } \\
\left.\mathrm{p}^{*}\right)\end{array}$} \\
\hline & $\begin{array}{l}\text { Tidak } \\
\mathrm{n}=18\end{array}$ & $\begin{array}{c}\mathrm{Ya} \\
\mathrm{n}=36\end{array}$ & \\
\hline \multicolumn{4}{|c|}{ Skor pengetahuan } \\
\hline Rerata (SD) & $65,10(14,70)$ & $74,11(11,15)$ & 0,004 \\
\hline Median & 61,53 & 73,07 & \\
\hline Rentang & $34,62-96,15$ & $38,46-92,31$ & \\
\hline \multicolumn{4}{|l|}{ Skor sikap } \\
\hline Rerata (SD) & $90,39(7,55)$ & $91,86(7,9)$ & 0,342 \\
\hline Median & 90,62 & 93,75 & \\
\hline Rentang & $75-100$ & $71,88-100$ & \\
\hline \multicolumn{4}{|c|}{$\begin{array}{l}\text { Skor dukungan } \\
\text { unit kerja/ } \\
\text { departemen }\end{array}$} \\
\hline Rerata (SD) & $49,53(15,30)$ & $52,43(16,03)$ & 0,567 \\
\hline Median & 50 & 50 & \\
\hline Rentang & $25-75$ & $25-75$ & \\
\hline
\end{tabular}

Karakteristik yang berhubungan dengan pemberian ASI ekslusif tertera pada Tabel 2.

Karakteristik yang mempunyai nilai $\mathrm{p}<0,25$, yaitu
Tabel 2. Karakteristik yang berhubungan dengan ASI ekslusif

\begin{tabular}{|c|c|c|c|}
\hline \multirow[t]{2}{*}{ Variabel } & \multicolumn{2}{|c|}{ Pemberian ASI eksklusif } & \multirow[t]{2}{*}{ Nilai $p$} \\
\hline & $\begin{array}{c}Y a \\
\mathrm{n}=48\end{array}$ & $\begin{array}{l}\text { Tidak } \\
\mathrm{n}=27\end{array}$ & \\
\hline \multicolumn{4}{|l|}{ Usia ibu } \\
\hline $\mathrm{X}(\mathrm{SD})$ & $30,15(2,7)$ & $31,4(3,8)$ & $\left.0,122^{*}\right)$ \\
\hline Median & 30 & 32 & \\
\hline Rentang & $23-36$ & $21-37$ & \\
\hline \multicolumn{4}{|l|}{ Pendidikan } \\
\hline Sarjana & 19 & 15 & 0,182 \\
\hline Bukan sarjana & 29 & 12 & \\
\hline \multicolumn{4}{|l|}{ Pekerjaan } \\
\hline Dokter & 10 & 9 & 0,232 \\
\hline Bukan dokter & 38 & 18 & \\
\hline \multicolumn{4}{|l|}{ Jenis persalinan } \\
\hline Spontan & 25 & 17 & 0,362 \\
\hline Bukan spontan & 23 & 10 & \\
\hline \multicolumn{4}{|l|}{$\begin{array}{l}\text { Jadwal jaga } \\
\text { malam }\end{array}$} \\
\hline Ya & 9 & 9 & 0,156 \\
\hline Tidak & 39 & 18 & \\
\hline \multicolumn{4}{|l|}{ Dukungan suami } \\
\hline $\mathrm{Ya}$ & 48 & 27 & 1 \\
\hline Tidak & 0 & 0 & \\
\hline \multicolumn{4}{|l|}{$\begin{array}{l}\text { Dukungan } \\
\text { pengasuh }\end{array}$} \\
\hline $\mathrm{Ya}$ & 33 & 12 & 0,039 \\
\hline Tidak & 15 & 15 & \\
\hline \multicolumn{4}{|l|}{$\begin{array}{l}\text { Dukungan } \\
\text { petugas kesehatan }\end{array}$} \\
\hline $\mathrm{Ya}$ & 40 & 16 & 0,021 \\
\hline Tidak & 8 & 11 & \\
\hline
\end{tabular}

Tabel 4. Analisis multivariabel berbagai faktor yang berhubungan

\begin{tabular}{lcc}
\hline Variabel & Nilai p & OR (IK95\%) \\
\hline Pengetahuan & 0,013 & 3,70 \\
& & $(1,31-10,40)$ \\
$\begin{array}{l}\text { Dukungan petugas } \\
\text { kesehatan }\end{array}$ & 0,031 & 3,45 \\
\hline
\end{tabular}

usia ibu, pendidikan, pekerjaan, jadwal jaga malam, dukungan pengasuh dan dukungan petugas kesehatan dimasukkan ke dalam analisis multivariabel.

Hubungan skor pengetahuan, sikap, dan dukungan unit kerja dengan pemberian ASI eksklusif tertera pada Tabel 3.

Pengujian statistik dengan Mann-Whitney 
menunjukkan perbedaan skor $\mathrm{p}<0,25$ hanya skor pengetahuan, selanjutnya analisis multivariat yang dilakukan dengan menggunakan cara backward stepwise, hasil model akhir tertera pada Tabel 4.

Variabel yang bermakna terhadap pemberian ASI eksklusif adalah pengetahuan dan dukungan petugas kesehatan $(\mathrm{p}<0,05)$.

\section{Pembahasan}

Penelitian ini melibatkan 75 orang responden yang memenuhi kriteria inklusi. Persentase keberhasilan ASI eksklusif didapatkan 64\% dan kegagalan 36\%. Hal tersebut lebih tinggi dibanding cakupan menyusui regional maupun global, tetapi masih lebih rendah daripada target cakupan pemberian ASI eksklusif yang ditetapkan Kementerian Kesehatan pada tahun 2014 sebesar 80 persen. $^{2}$

Dari tiga variabel yang diteliti, hanya pengetahuan yang menunjukkan hubungan bermakna. Variabel dukungan petugas kesehatan merupakan faktor perancu berhubungan dengan pemberian ASI eksklusif. Penelitian sebelumnya yang dilakukan Roig dkk, ${ }^{8}$ Obilade dkk, ${ }^{9}$ dan Haroon dkk ${ }^{10}$ melaporkan hubungan antara pengetahuan dan pemberian ASI eksklusif, tetapi ketiga penelitian tersebut dilakukan bukan pada tenaga kesehatan. Hubungan pengetahuan dengan pemberian ASI eksklusif sesuai dengan teori yang dikeluarkan oleh Notoatmojo ${ }^{15}$ bahwa pengetahuan merupakan domain yang paling penting untuk terbentuknya tindakan pada seseorang. Perilaku yang didasarkan pengetahuan akan lebih bertahan daripada perilaku yang tidak didasari pengetahuan.

Sikap merupakan faktor lain yang juga berhubungan dengan praktik pemberian ASI eksklusif. Kami tidak menemukan hubungan antara sikap dan pemberian ASI eksklusif. Hasil tersebut berbeda dengan penelitian Abdullah dan Ayubi ${ }^{11}$ yang melaporkan variabel sikap merupakan faktor paling dominan dalam pemberian ASI eksklusif. Ibu pekerja yang mempunyai sikap mendukung berpeluang 5 kali memberikan ASI eksklusif dibanding dengan ibu yang mempunyai sikap kurang mendukung. Perbedaan ini mungkin disebabkan oleh subjek yang berbeda dan pengukuran dengan skala sikap yang berbeda.

Dukungan unit kerja/departemen yang dimaksud pada penelitian ini berupa total skor dukungan pimpinan (kebijakan cuti, waktu, keringanan waktu kerja, dan waktu memerah ASI), ketersediaan fasilitas (ruang menyusui, lemari es penyimpan ASI), dan dukungan rekan kerja tidak berhubungan dengan pemberian ASI eksklusif. Penelitian Abdullah dan Ayubi ${ }^{11}$ sebelumnya melaporkan hubungan ketersediaan fasilitas menyusui berupa tempat memerah ASI, peralatan untuk memerah dan menyimpan ASI dengan praktik pemberian ASI eksklusif. Namun, dukungan pimpinan berupa kebijakan keringanan waktu bekerja dan waktu memerah tidak berhubungan. Kami tidak melakukan analisis ketersediaan fasilitas dan dukungan pimpinan secara terpisah sehingga hasilnya tidak sama.

Dukungan petugas kesehatan yang merupakan variabel perancu berhubungan dengan praktik pemberian ASI eksklusif. Pada penelitian sebelumnya di Prancis, Labaree $\mathrm{dkk}^{16}$ melaporkan bahwa ibu yang mendapat dukungan dokter selama menyusui lebih banyak yang memberikan ASI eksklusif dibanding yang tidak mendapat dukungan. Penelitian di Australia, $\mathrm{Li} \mathrm{dkk}^{17}$ melaporkan hasil ibu yang mendapatkan dukungan dari dokter mempunyai kemungkinan menyusui bayinya 10-17 kali dibanding yang tidak. Britton dkk, ${ }^{18}$ melalui studi metaanalisis, melaporkan bahwa dukungan tenaga kesehatan profesional memperlama durasi menyusui. Ketiga penelitian tersebut dilakukan pada ibu menyusui tanpa melihat profesi tenaga kesehatan atau bukan.

Kelebihan penelitian kami merupakan penelitian pertama yang meneliti praktik pemberian ASI eksklusif khusus di kalangan tenaga kesehatan, khususnya dokter, bidan, dan perawat. Kelemahan penelitian kami adalah penggunaan kuesioner sebagai alat ukur tanpa kelanjutan wawancara yang lebih mendalam.

\section{Kesimpulan}

Pengetahuan berhubungan dengan praktik pemberian ASI eksklusif. Sikap dan dukungan unit kerja atau departemen tidak berhubungan dengan praktik pemberian ASI eksklusif. Dukungan petugas kesehatan merupakan variabel perancu yang berhubungan dengan pemberian ASI eksklusif.

\section{Daftar pustaka}

1. United Nations for Children's fund. Breastfeeding. Diunduh 26 Agustus 2015. Didapat dari: http://www. 
Ariani dkk: Hubungan pengetahuan, sikap, dan dukungan unit kerja/departemen dengan pemberian ASI eksklusif pada tenaga kesehatan

unicef.org/nutrition/index_24824.html.

2. Kementerian Kesehatan Republik Indonesia. Riset kesehatan dasar (Riskesdas) 2013 Diunduh 26 Mei 2015.

Didapat dari: http:// www.depkes.go.id/ resources/ download/ generall Hasil\%20Riskesdas\% 202013.pdf.

3. Kementerian Kesehatan Republik Indonesia. Profil kesehatan Jawa Barat tahun 2012 Diunduh 15 Agustus 2015. Didapat dari: http:// www. depkes. go.id/ resources/ download/profil/PROFIL_KES_PROVINSI_2012/ 12_ Pofil_Kes. Prov. JawaBarat_2012. pdf.

4. Horta BL, Victoria CG. Short term effect of breastfeeding: a systematic review. 2011. Diunduh 4 September 20015. Didapat dari: http://apps.who.int /iris/ bitstream/ 10665/95585/1/9789241506120_eng.pdf.

5. Lamberti LM, Zakarija-Grković I, Walker CLF, Theodoratou E, Nair H, Campbell H, dkk. Breastfeeding for reducing the risk of pneumonia morbidity and mortality in children under two: a systematic literature review and meta-analysis. BMC Public Health 2013: 13:S18.

6. Edmond KM, Zandoh C, Quigley AM, Amenga-Etego S, Owusu-Agyei S, Kirkwood BR. Delayed breastfeeding initiation increases risk of neonatal mortality. Pediatrics 2006;117:e380-6.

7. Jones G, Stekee RW, Black RE, Bhutta ZA, Morris SS, Bellagio Child Survival Study. Child survival II. How many deads can we prevent this year? Lancet 2003;362:65-71

8. Roig AO, Martínez MR, García JC, Hoyos SP, Navidad GL, Álvarez JCF. Factors associated to breastfeeding cessation before 6 months. Rev Latino-Am Enfermagem 2010;18:373-80.

9. Obilade TT. The knowledge, attitude and practice of exclusive breastfeeding among mothers in two semiurban areas around a Baby Friendly Hospital Initiative (BFHI) designated hospital in Lagos State, Nigeria. Int
Arch Med 2015:15:1-13

10. Haroon S, Das JK, Salam RA, Imdad A, Bhutta ZA. Breastfeeding promotion interventions and breastfeeding practices: a systematic review. BMC Public Health 2013;13:S3-20.

11. Abdullah GI, Ayubi D. Determinan perilaku pemberian air susu ibu eksklusif pada ibu pekerja. KesMas 2013;7:299-303

12. Johnston ML, Esposito N. Barriers and facilitators for breastfeeding amomg working women in the united states. J Obstet Gynacol Neonatal Nurs. 2007:36:9-20.

13. Ahluwalia IB, Morrow B, Hsia J. Why do women stop breastfeeding? findings from the pregnancy risk assessment and monitoring system. Pediatrics 2005;116:1408-12.

14. Mari H. Breasfeeding: factor associated with the continuation of breastfeeding, the current situation in Japan and recommendation for further research. J Med Invest 2007;54:224-34.

15. Notoatmodjo $S$, penyunting. Konsep perilaku dan perilaku kesehatan Edisi ke-1. Jakarta: Rhineka Cipta; 2003.

16. Labarere J, Gelbert-Baudino N, Ayral AS, Duc C, Berchoteau M, Bouchon N, dkk. Efficacy of beastfeding support provided by trained clinicians during an early, routine, preventive visit: a prospectiv, randomized open trial of 2262 mother-infant pairs. Pediatrics 2005;115:e139-46.

17. Li L, Zhang M, Cott A, Binns CW. Factor associated wiyh the initiation and duration of breastfeeding by chinese mother in Perth, Westtern Australia. J Hum Lact 2004;20:188-95.

18. Britton, McCormick F Renfew MJ, Wade A, King SE. Support for breastfeeding mothers (Review). Intervention for promoting the intiation of breastfeeding. Chohrane Database Sys Rev 2005;(2)CD001688. 